\title{
PEGADA HIIDRICA DA PRODUÇÃO DE LEITE IN NATURA: UMA ANÁLISE DAS PRINCIPAIS REGIÕES PRODUTORAS DO RIO GRANDE DO SUL
}

\author{
WATER FOOTPRINT OF IN NATURA MILK PRODUCTION: AN \\ ANALYSIS OF THE MAIN PRODUCING REGIONS \\ OF RIO GRANDE DO SUL
}

Data de submissão: 02/01/2017 Aceite: 22/10/2017

Júlia Elisabete Barden ${ }^{1}$

Fernanda Cristina Wiebusch Sindelar ${ }^{2}$ Bruno Nonnemacher Buttenbender ${ }^{3}$

Gustavo Rodrigo da Silva ${ }^{4}$

\section{RESUMO}

Tendo em vista a importância econômica e social da produção de leite in natura para o Rio Grande do Sul, torna-se relevante avaliá-la sob o ponto de vista da sustentabilidade ambiental. Uma das formas para isso é por meio da estimativa da pegada hídrica para as produções pecuárias, que contribui tanto para o conhecimento sobre o consumo de água utilizada quanto para a promoção da gestão e da conservação desse recurso. Diante disso, o objetivo deste trabalho é estimar a pegada hídrica da produção do leite in natura para as principais regiões produtoras de leite no Rio Grande do Sul: 77 municípios que integram os Coredes Fronteira Noroeste, Produção e Vale do Taquari. Para tanto, foi utilizada uma metodologia padrão para estudos dessa natureza, sendo os dados coletados de diferentes fontes: do Instituto Brasileiro de Geografia e Estatística (IBGE, 2014) no que concerne à produção de leite e à quantidade de vacas ordenhadas; e da literatura consolidada no que diz respeito a parâmetros preestabelecidos. Os resultados indicam que, quanto mais produtivo for o rebanho, maior é a sua capacidade de conversão em relação à transformação do alimento consumido em produto final, o que significa que, quanto maior for a produtividade de leite, menor será a sua pegada hídrica.

Palavras-chave: Pegada Hídrica. Produção de Leite. Coredes.

\footnotetext{
1 Possui graduação em Ciências Econômicas pela Universidade de Santa Cruz do Sul, mestrado em Economia Rural pela Universidade Federal do Rio Grande do Sul e doutorado em Economia com ênfase em Economia do Desenvolvimento pela Universidade Federal do Rio Grande do Sul. Atualmente é professora e pesquisadora do Centro Universitário UNIVATES. Lajeado. Rio Grande do Sul. Brasil. E-mail: jbarden@univates.br 2 Possui graduação em Ciências Econômicas pelo Centro Universitário Univates, mestrado em Economia pela Pontifícia Universidade Católica do Rio Grande do Sul e doutorado em Ambiente e Desenvolvimento pelo Centro Universitário Univates. Lajeado. Rio Grande do Sul. Brasil. E-mail: fernanda@univates.br

3 Possui graduação em Administração pela Universidade Regional do Noroeste do Estado do Rio Grande do Sul e mestrado em andamento em Ambiente e Desenvolvimento pela Unidade Integrada Vale do Taquari de Ensino Superior. Lajeado. Rio Grande do Sul. Brasil. E-mail: brunonbuttenbender@gmail.com

4 Possui graduação em andamento em Ciências Biológicas do Centro Universitário Univates. Lajeado. Rio Grande do Sul. Brasil. E-mail: guhrs@hotmail.com
} 


\section{ABSTRACT}

According to the economic and social importance of the production of in natura milk for the RS, it is also relevant to evaluate the point of view over the environmental sustainability, and one way to do it is through water footprint. The estimation of the water footprint for livestock production contributes to the knowledge about the water consumption, as well as helps to promote the management and conservation of this resource. Therefore, this study's objective aims to estimate the water footprint of in natura milk production for the main regions in milk production of RS: Coredes Fronteira Noroeste, Produção and Vale do Taquari, in which are covered 77 municipalities. The methodology used is standard for studies of this nature, being the data collected in two distinct ways, concerning relative to milk production and the amount of dairy cattle were collected by municipalities from the Brazilian Institute of Geography and Statistics (IBGE, 2014); and in consolidated literature, relative to pre-established parameters. The results show that the more productive is the herd, the bigger is its capacity of the feed conversion into product, in other words, the bigger is one's the productivity, the smaller is its water footprint.

Keywords: Water Footprint. Milk Production. Coredes.

\section{INTRODUÇÃO}

O Brasil é um dos principais produtores mundiais de leite, ficando atrás apenas dos Estados Unidos, da Índia e da China. Segundo dados da Organização das Nações Unidas para a Alimentação e a Agricultura (FAO, 2016), em 2013 o país produziu 35,67 milhões de toneladas de leite de vaca, o que representou $5,6 \%$ da produção mundial. Em termos econômicos, o valor da produção em 2014 representou R\$ 33,786 bilhões. Observa-se, ainda, que a cadeia leiteira está concentrada nos estados de Minas Gerais, Rio Grande do Sul, Paraná, Goiás e Santa Catarina, os quais foram responsáveis em 2014 por aproximadamente $72 \%$ da produção nacional (IBGE, 2016).

No Rio Grande do Sul, segundo maior produtor de leite do Brasil, a produção também se concentra em alguns espaços; em 2014, por exemplo, as principais regiões produtoras foram as dos Coredes ${ }^{5}$ Fronteira Noroeste, Produção e Vale do Taquari. No estado, a atividade está vinculada à agricultura familiar, principalmente nas pequenas e médias propriedades, e gera, normalmente, pequenos volumes de produção. Tais características fazem com que essa atividade exerça importante impacto econômico e social, sobretudo nas regiões mais produtoras.

Para o desenvolvimento da produção leiteira, assim como das demais atividades pecuárias, são consumidos, entretanto, diversos recursos naturais, como a água, um recurso escasso. A pressão exercida sobre o uso da água ocorre ao longo de todas as etapas da cadeira produtiva do leite: produção, processamento e varejo. Diante disso, monitorar o montante de água utilizada permite avaliar o impacto causado pelo ser humano sobre o meio ambiente e compreender como ele pode ser mitigado, tendo em vista a busca pelo equilíbrio e pela sustentabilidade.

Uma das primeiras etapas para efetuar essa análise é identificar o volume de recursos envolvidos para, posteriormente, fazer a sua gestão em busca de melhor uso e conservação. Especificamente em relação à água, uma das formas de identificação consiste na avaliação da pegada hídrica. A pegada hídrica é definida como um instrumento abrangente capaz de estimar a apropriação de recursos hídricos na produção e no consumo, podendo ser empregada em diferentes contextos e projetos.

Dessa forma, o objetivo deste trabalho consiste em estimar a pegada hídrica da produ-

5 Os Conselhos Regionais de Desenvolvimento (Coredes) são uma classificação política, tendo sido criados em 1994 pelo Governo do Estado para servirem de fórum de discussão e decisão a respeito de políticas e ações voltadas ao desenvolvimento regional. Atualmente, o Rio Grande do Sul é formado por 28 Coredes. 
ção do leite in natura para as principais regiões produtoras de leite no Rio Grande do Sul: Coredes Fronteira Noroeste, Produção e Vale do Taquari. Para isso, este texto está estruturado em quatro partes, além desta introdução. A seguir, faz-se a conceituação da pegada hídrica. Após, são apresentados os procedimentos metodológicos utilizados e os resultados do estudo. Já na quinta e última seção, são expostas as considerações finais.

\section{FUNDAMENTAÇÃO TEÓRICA}

Para o seu desenvolvimento, os seres humanos são dependentes de água. A cada ano, consome-se uma quantidade significativa de água para uso doméstico, agrícola e industrial. Contudo, por tratar-se de um recurso limitado, seu uso não pode ser desmedido, assim como sua poluição deve ser minimizada (HOEKSTRA et al., 2011).

Nesse contexto, nos últimos anos diversos indicadores para a avaliação do uso dos recursos hídricos vêm sendo desenvolvidos. Um deles é a pegada hídrica - water footprint -, proposto por Arjen Y. Hoekstra em 2002, com a finalidade de propiciar a análise da conexão entre o consumo humano e a apropriação mundial de água doce, de maneira direta e indireta (HOEKSTRA et al., 2011). Em outras palavras, trata-se de um conceito facilitador enquanto indicador quantitativo, capaz de acessar não somente os volumes de água consumidos em determinado ambiente, mas também o período em que ocorre esse consumo.

Segundo Hoekstra (2009), a pegada hídrica total pode ser classificada em três tipos: pegada hídrica azul - refere-se ao consumo de água doce superficial e subterrânea, que pode estar em lagos, rios e aquíferos, informando o consumo de água utilizada pelos seres humanos e para a conservação da vida nos ecossistemas em determinado período de tempo; pegada hídrica verde - indica o consumo de água verde precipitada sobre a terra que não escoa ou recarrega aquíferos, sendo armazenada no solo, sobre este ou na vegetação, ou seja, o volume de água da chuva despendida durante o processo produtivo, em especial o agrícola e florestal; e pegada hídrica cinza - relativa ao volume de água necessário para diluir os poluentes de modo que a qualidade de água em seu estado natural possa ser mantida em condições adequadas.

Mekonnen e Hoekstra (2010), ao estudarem a pegada hídrica azul, verde e cinza de animais de criação e de produtos de origem animal destacaram a necessidade de considerar a água consumida diretamente pelo animal, a água embutida nos alimentos que este consome e a água consumida em processos e serviços, como, por exemplo, na limpeza do ambiente onde vive. Segundo os autores, a estimativa da pegada hídrica para as produções pecuárias contribui tanto para o conhecimento sobre o consumo de água utilizada na atividade quanto para a promoção da gestão e da conservação desse recurso por parte dos atores das cadeias produtivas.

Já para Hoekstra et al. (2011), a pegada hídrica é entendida como a soma do volume total de água doce que é utilizado direta ou indiretamente no processo produtivo de todas as etapas da cadeia de produção de determinado item (Figura 1). 
Figura 1 - Pegada hídrica direta e indireta em cada estágio da cadeia produtiva de suprimento de um produto de origem animal

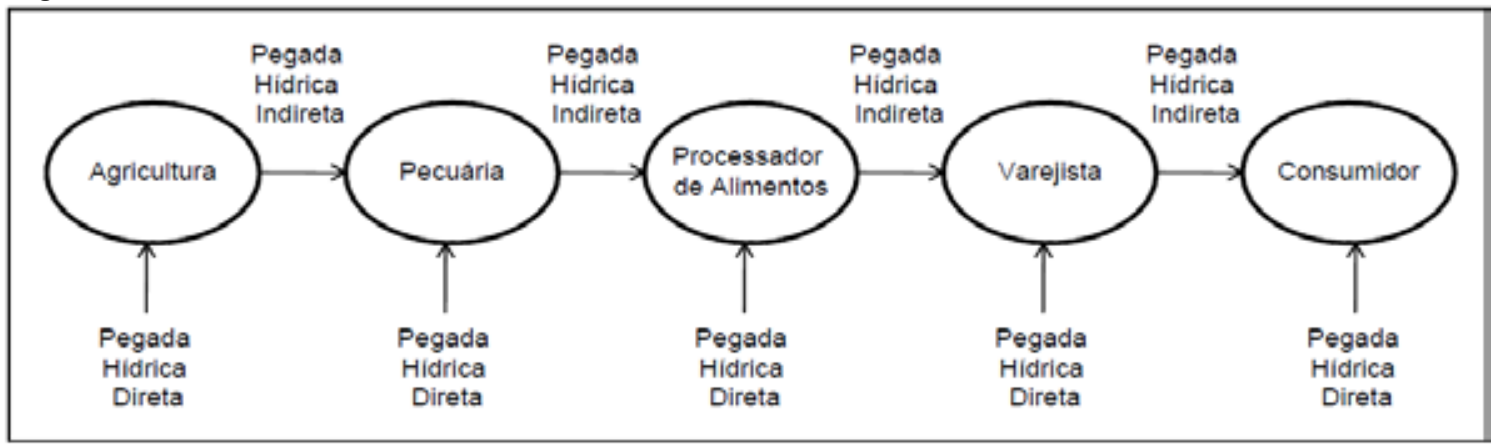

Fonte: Hoekstra et al. (2011, p. 21).

Os autores também afirmam que, para estimar a pegada hídrica de um produto, é necessário em primeiro lugar entender a forma como ele é produzido. Dessa maneira, na produção de leite, não é possível projetar uma pegada hídrica linear, mas, sim, uma estrutura chamada "árvore do produto", devido às diferentes variáveis que participam do cálculo, como a pegada hídrica dos diversos itens presentes na alimentação do animal (cereais, oleaginosas, pastos, forragens, entre outros) (HOEKSTRA et al., 2011).

A pegada hídrica caracteriza-se, assim, como um indicador amplo e multidimensional do consumo de água por fonte e do volume e tipo de poluição dos recursos hídricos. Em outras palavras, pode comunicar não somente sobre o volume, mas também sobre o tipo de água que foi utilizada (azul, verde ou cinza), bem como quando e onde. Esse conceito possibilita, por exemplo, que seja quantificado o volume total de recursos hídricos necessários à produção de bens e serviços consumidos em determinado ambiente (HOEKSTRA et al., 2011). Dessa maneira, para a estruturação desses valores, deve-se considerar a água envolvida em toda a cadeia de produção, assim como as características específicas da região analisada, além das características ambientais e tecnológicas disponíveis no ambiente em questão (CHAPAGAIN; HOEKSTRA, 2004; CARMO et al., 2007).

Destaca-se, ainda, que a pegada hídrica consiste em uma ferramenta analítica simplificada, que informa sobre o uso dos recursos hídricos, contribuindo para a compreensão dos pontos críticos. Contudo, ela não é capaz de informar sobre a gravidade dos impactos ambientais locais decorrentes do uso e da poluição da água ou sobre o que é necessário fazer para minimizar os seus impactos. Além disso, cabe ressaltar que a avaliação da pegada hídrica é uma ferramenta parcial, que deve ser adotada em conjunto com outros tipos de análises, para permitir a compreensão de todas as questões relevantes durante a tomada de decisão (HOEKSTRA et al., 2011).

\section{PROCEDIMENTOS METODOLÓGICOS}

Os objetivos e os contextos da avaliação da pegada hídrica podem ser variados, uma vez que a metodologia para a contabilização da pegada hídrica permite que esta seja estimada para uma etapa do processo, um produto, os consumidores, as empresas, um setor ou determinada região, por exemplo. No presente estudo, foi utilizada a metodologia para estimar a pegada hídrica da produção do leite in natura para as principais regiões produtoras de leite no Rio Grande Sul. considerando-se somente a pegada hídrica direta e indireta das duas etapas iniciais da cadeia produtiva: agricultura e pecuária. 
A estimativa levou em conta parâmetros já estimados e encontrados na literatura consolidada sobre o tema, bem como dados sobre produção de leite e rebanho (ano de 2014) das seguintes regiões do Rio Grande do Sul: Fronteira Noroeste, Produção e Vale do Taquari. Essas regiões foram definidas a partir de suas importantes participações na produção de leite in natura, já que juntas, localizadas na metade Norte do estado, produzem aproximadamente $26 \%$ do total produzido no estado: Noroeste produz 9,1\%, Produção, 8,8\%, e Vale do Taquari, 7,9\% (Figura 2).

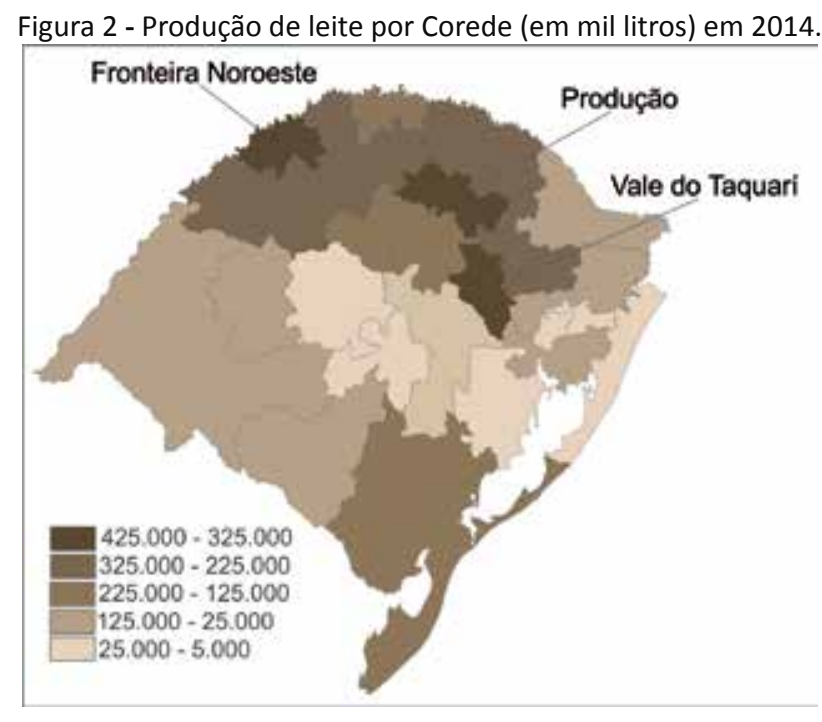

Fonte: FEE (2016).

Em termos de quantidade de produção anual, o Corede Produção, formado por 21 municípios, foi responsável em 2014 por 414.338 mil litros de leite. Já o Corede Fronteira Noroeste, constituído por 20 municípios, produziu 398.526 mil litros de leite, enquanto que no Vale do Taquari, composto por 36 municípios, a produção declarada foi de 371.009 mil litros de leite.

No que diz respeito à quantidade de animais de rebanho leiteiro, o Corede Fronteira Noroeste apresenta o maior número (110.957), seguido pela Região do Vale do Taquari (107.435) e pelo Corede Produção (88.971). Ademais, tendo em vista a especialização da produção leiteira nessas regiões, nelas estão localizados a maioria dos municípios com os maiores índices de produtividade (conforme Apêndices).

A metodologia utilizada para o cálculo da pegada hídrica é padrão para estudos dessa natureza, conforme estabelecido por Hoekstra (2009). Para a estimativa da pegada hídrica de um produto de origem animal, é necessário, primeiramente, calcular a pegada hídrica do animal em si, somando-se a isso a pegada hídrica associada ao alimento consumido por este, a água ingerida enquanto bebida e a água utilizada para serviços relacionados à atividade. Para isso, utiliza-se a seguinte fórmula:

$$
\begin{aligned}
& P I_{\text {Bovino }}=P_{A \text { limento }}+P I_{\text {Bebida }}+P I_{\text {Serviço }} \\
& \text { Onde: } \\
& \left.\mathrm{PH}_{\text {Bovino }}=\text { Pegada hídrica bovino total (medida em } \mathrm{m}^{3}\right) \\
& \mathrm{PH}_{\text {Alimento }}=\text { Pegada hídrica do alimento consumido }\left(\text { medida em } \mathrm{em}^{3}\right. \text { ) } \\
& \mathrm{PH}_{\text {Bebida }}=\text { Montante de água bebida pelo animal (medida em } \mathrm{em}^{3} \text { ) } \\
& \mathrm{PH}_{\text {Serviço }}=\text { Montante de água envolvida em serviços (medida em } \mathrm{m}^{3} \text { ) }
\end{aligned}
$$


Para o cálculo da pegada hídrica do alimento, considera-se a razão da pegada hídrica do total de cada um dos produtos envolvidos na alimentação dos bovinos, somado ao montante de água utilizado para a mistura destes, pela população total de animais, segundo a fórmula a seguir:

$\boldsymbol{P I}_{\text {alimento }}=\frac{\sum_{p=1}^{n}\left(a \lim \text { ento } \times P_{\text {produção }}\right)+P_{\text {mistura }}}{\text { População }}$

O valor referente à pegada hídrica de cada um dos ingredientes presentes na alimentação dos bovinos foi retirado da literatura: quanto à alimentação descrita como concentrada, os dados foram extraídos de Mekonnen e Hoekstra (2010); no que concerne à alimentação volumosa, as informações foram provenientes de Bouwman et al. (2005); e em relação aos dados sobre rebanho e produção, estes foram coletados da Pesquisa Pecuária Municipal do IBGE para os 77 municípios que integram os três Coredes (Fronteira Noroeste, Produção e Vale do Taquari) para o ano de 2014, cujos resultados constam nos Apêndices e são discutidos na próxima seção.

Cabe ressaltar que, embora outros estudos tomem como base para seus cálculos a média estimada destes valores durante períodos mais longos, este artigo optou por analisar especificamente os dados referentes ao ano de 2014, visto que a pecuária desenvolvida no estado está atravessando um "processo de relocalização espacial e de reorganização da produção" e que o crescimento e a especialização da atividade não seguem a mesma tendência em todas as regiões (Schumacher; Marion Filho, 2013, p. 39).

Destaca-se, ainda, que, na fórmula $\mathrm{PH}_{\text {alimento' }}$ a variável entendida como alimento é encontrada ao multiplicar a taxa média de eficiência pelo total de produção $(\mathrm{kg})$ :

$a \lim$ ento $=T M E \times$ produção

Onde:

TME = Taxa média de eficiência na conversão do alimento.

O cálculo da taxa média de eficiência (TME) de conversão do alimento é obtido pela razão da taxa de alimento necessária (TAN) ( $\mathrm{kg}$ ) e da produtividade de cada animal (kg/leite/ano), conforme a seguinte fórmula:

$T M E=\frac{T A N}{\text { Produtividade }}$

Onde:

TME = Taxa média de eficiência na conversão do alimento em produto

A TAN refere-se ao montante de alimento consumido, sendo o seu valor obtido por meio da multiplicação do peso vivo médio dos animais (kg) pelo índice de alimentação diária destes (IAD). Neste estudo, os valores relativos a essas duas variáveis foram extraídas de Hendy et al. (1995).

A literatura também informa que a alimentação dos bovinos é dividida em roughage (volumosa, entendida como pasto e demais comidas cruas) e concentrate (concentrada, entendida como ração, oleaginosas, cereais e outros), os quais apresentam componentes diferentes e, 
portanto, têm valores de pegada hídrica também distintos. Para estimar a quantidade de cada um, considera-se que o alimento concentrado seja expresso pelo resultado da alimentação multiplicado pela fração de alimento concentrado por categoria de animal, enquanto o alimento volumoso corresponde à diferença entre o alimento concentrado e o total de alimento consumido.

As informações relativas aos coeficientes de alimentos concentrados e volumosos também foram extraídas de estudos anteriores. A fração de alimento concentrado dentro da alimentação dos bovinos foi extraída de Hendy et al. (1995); os dados sobre o sistema de produção foram provenientes de Seré e Steinfeld (1996); a composição do alimento concentrado foi extraída de Wheeler et al. (1981 apud MEKONNEN; HOEKSTRA, 2010); e a composição do alimento volumoso foi retirada de Bouwman et al. (2005). Já os valores de água ingerida pelo rebanho enquanto bebida, que incide sobre o $\mathrm{PH}_{\text {Bebida }}$ e o consumo de água utilizada para os serviços ( $\mathrm{PH}$ Serviçol foram extraídos de Chapagain e Hoekstra (2003).

A partir da contabilização da pegada hídrica total dos bovinos, obtida por meio da soma da pegada hídrica do alimento, da bebida e do serviço, é possível contrapor os resultados encontrados à produtividade, na razão entre os dois, para assim estipular a pegada hídrica da produção do leite bovino, expressa em litros de água por litros de leite $\left(\mathrm{I}_{\mathrm{a}} / \mathrm{I}_{\mathrm{l}}\right)$.

$$
\boldsymbol{P I}_{\text {Leite }}=\frac{P_{\text {Bovino }}}{P_{\text {rodutividad }}}
$$

Na seção a seguir, apresenta-se a análise dos resultados.

\section{ANÁLISE DOS RESULTADOS}

No que se refere à alimentação dos animais, encontrou-se um resultado de $3.640,88 \mathrm{~kg}$ de alimento por bovinos de leite por ano. Desse montante, $10 \%$ encontram-se em forma de alimento concentrado, e 90\%, em forma de alimentação volumosa (HENDY et al., 1995; BOUWMAN et al.; 2005; MEKONNEM; HOEKSTRA, 2010).

Conforme Wheeler et al. (1981 apud MEKONNEN; HOEKSTRA, 2010), da alimentação concentrada, $70,58 \%$ são cereais, $23,52 \%$ são oleaginosas, e $5,9 \%$ são classificados como outros. No que tange à alimentação volumosa, Bouwman et al. (2005) sugerem que $45 \%$ são pasto, $41 \%$ são forragem e 14\% são classificados como outros (farelos, palha e folhas) (MEKONNEN; HOEKSTRA, 2010).

Dessa maneira, levando-se em consideração as diferentes pegadas hídricas da produção desses alimentos, estimou-se que o montante da pegada hídrica da alimentação dos bovinos de leite é de $1.498,28 \mathrm{~m}^{3}$ de água por cabeça/ano. Além disso, conforme Chapagain e Hoekstra (2003), com os acréscimos de água ingerida enquanto bebida $\left(14,6 \mathrm{~m}^{3} / \mathrm{ano}\right)$ e de água utilizada enquanto serviços (1,825 $\left.\mathrm{m}^{3} / \mathrm{ano}\right)$, chega-se a um valor final de $1.514,71 \mathrm{~m}^{3}$ de água consumida direta e indiretamente por cabeça/ano.

Quanto à pegada hídrica da produção de leite bovino, que é identificada pela razão dos litros de água consumidos direta e indiretamente na produção do leite pela sua produtividade anual, é importante ressaltar que o Brasil apresenta uma média em todo o território nacional de cerca de 994,2 litros de água necessários para a produção de um litro de leite $\left(I_{a} / I_{1}\right)$, média essa mais de duas vezes maior do que a do estado do Rio Grande do Sul, com 449,2 litros de água por litro de leite.

Nas regiões analisadas neste estudo, o melhor desempenho em termos da pegada hídrica é o Corede Produção, onde são consumidos em média cerca de 345,7 litros de água na 
produção de um litro de leite $\left(I_{a} / I_{1}\right)$, seguido pelo Corede Fronteira Noroeste, que necessita aproximadamente de 448,2 litros de água, e pelo Vale do Taquari, com uma demanda em torno de 487,9 litros de água para a produção de um litro de leite. Contudo, ressalta-se ainda que, mesmo nessas regiões mais produtoras, existem disparidades internas.

$\mathrm{Na}$ esfera municipal, os municípios com maior destaque são Casca $\left(280,5 \mathrm{I}_{\mathrm{a}} / \mathrm{I}_{\mathrm{l}}\right)$ e Pontão $\left(297,0 I_{2} / I_{1}\right)$, ambos localizados na região do Corede Produção, que, dentre os três Coredes analisados, é o que tem menor pegada hídrica, seguidos pelo município de Estrela, situado no Vale do Taquari $\left(304,9 I_{a} / l_{1}\right)$ - a produtividade média de cada um desses municípios é de $5.399,5.100$ e $4.968 \mathrm{l} / \mathrm{vaca} / \mathrm{ano}$, respectivamente. Por outro lado, as maiores taxas de pegada hídrica nas mesmas regiões dizem respeito aos municípios de Poço das Antas $\left(665,8 \mathrm{I}_{\mathrm{a}} / \mathrm{I}_{1}\right)$, Lajeado $\left(673,2 \mathrm{I}_{\mathrm{a}} /\right.$ $\left.1_{1}\right)$ e Bom Retiro do Sul $\left(673,2 I_{a} / I_{1}\right)$, todos pertencentes ao Vale do Taquari, com produtividade de $2.275,2.250$ e $2.250 \mathrm{I} / \mathrm{vaca} / \mathrm{ano}$, respectivamente.

Em síntese, os resultados indicam que, quanto mais produtivo for o rebanho, maior é a sua capacidade de conversão em relação à transformação do alimento consumido em produto final, ou seja, quanto maior for a produtividade de leite de determinado local, menor será a sua pegada hídrica. Para tanto, é importante que as regiões procurem se especializar na atividade, aumentando a produtividade do rebanho, a fim de minimizar seus impactos no que concerne ao consumo de água e garantir a sustentabilidade da atividade.

Nesse sentido, dentre os principais fatores que têm contribuído para o aumento da produtividade da produção de leite no Brasil no período recente, estão: a expansão da área de pastagens; o aumento do número de vacas ordenhadas; o aumento da produtividade dos fatores de produção a partir da adoção de novas tecnologias; a melhoria na alimentação dos animais com o uso de alimento concentrado, de técnicas de rotação de pastagens e do sistema de produção intensiva; as técnicas de manejo, sendo importante destacar as diferenças entre as regiões brasileiras, o que não permite a adoção de um único modelo; a sanidade e genética (o gado de leite brasileiro não é especializado, sendo, em boa medida, resultado da cruza com gado de corte) (FERRO et al., 2007).

\section{CONSIDERAÇÕES FINAIS}

A estimativa da pegada hídrica da produção de leite in natura das principais regiões produtoras do Rio Grande do Sul indica que, embora se trate de uma importante atividade em termos econômicos e sociais, esta consome um volume significativo de água, de forma direta e indireta. A fim de que haja equilíbrio e sejam preservadas as condições para a sustentabilidade da atividade, faz-se necessária a identificação do uso deste recurso.

A avaliação da sustentabilidade consiste na primeira etapa para a gestão dos recursos em busca do equilíbrio. Por meio da mensuração dos volumes consumidos ao longo da atividade, torna-se possível identificar em cada fase os pontos críticos de consumo.

A partir dos resultados alcançados, identificou-se que as regiões e os municípios do Rio Grande do Sul com maior especialização da atividade impactam menos o uso da água na fase de produção, fato que reforça a necessidade de investimentos na especialização, pois, além de proporcionar ganhos econômicos, permite igualmente menor pressão sobre o uso de recursos naturais.

Como limitação do estudo, cabe mencionar que se utilizou como referência para consumo de água pelos bovinos parâmetros já divulgados na literatura, cujos valores, entretanto, podem diferir de acordo com o tipo de alimentação fornecida aos animais. Por exemplo, propriedades que utilizam mais pastagem na alimentação dos animais acabam por apresentar uma pe- 
gada hídrica menor, visto que sua alimentação se baseia mais no alimento volumoso e menos no alimento concentrado. Assim, para a avaliação da sustentabilidade da atividade leiteira, sugerese em estudos futuros buscar informações detalhadas acerca das características da alimentação fornecida aos animais.

\section{REFERENCIAS}

BOUWMAN, A. F.; VAN DER HOEK, K. W.; EICKHOUT, B.; SOENARIO, I. Exploring changes in world ruminant production systems. Agricultural Systems, n. 84, p. 121-153, 2005.

CARMO, R. L.; OJIMA, A. L. R. O.; OJIMA, R.; NASCIMENTO, T. T. Água virtual, escassez e gestão: o Brasil como grande 'exportador' de água. Ambiente \& Sociedade, Campinas, v. 10, n. 2, p. 83-96, 2007.

CARRA, Sofia Helena Zanella; SCHNEIDER, Vania Elisabete Schneider. Pegada Hídrica Cinza dos Suínos Abatidos no Corede Serra/ RS - Brasil. Scientia Cum Industria (SCl. CUM IND.), v. 3, n. 2, p. 55-58, 2015.

CHAPAGAIN, A. K.; e HOEKSTRA, A. Y. Virtual water flows between nations in relation to trade in livestock products, Value of Water Research Report Series No. 13, UNESCO-IHE, Delft, the Netherlands, 2003. Disponível em: <http://waterfootprint.org/media/downloads/ Report13.pdf>. Acesso em: 01 set. 2016.

CHAPAGAIN, A. K.; e HOESTRA, A. Y. Water Footprint of nations, Value of Water Research Report Series No. 16, UNESCO-IHE, Delft, The Netherlands, 2004. Disponível em: <http:// waterfootprint.org/media/downloads/ Report16Vol1.pdf>. Acesso em: 01 set. 2016.

FERRO, A. B.; CARVALHO, M. P. de; MARTINS, P. do C.; SPERS, R. G.; ROCHELLE, T. C. P. Contextualização da cadeia produtiva do leite no Brasil. In: Cenários para o leite no Brasil em 2020. Juiz de Fora: Embrapa Gado de Leite, p. 21-72, 2007.

FINAMORE, E. B.; MAROSO, M. T. D. A dinâmica da Cadeia de lácteos gaúcha no período de 1990 a 2003: um enfoque no COREDE Nordeste.
In: 3 Encontro de Economia Gaúcha... Porto Alegre: Fundação de Economia e Estatística, 2006. Disponível em: <http://www.fee.rs.gov. $\mathrm{br} / 3$ eeg/Artigos/m01t01.pdf>. Acesso em: 18 jan. 2016.

food and agriculture organization of the united nations (fao). FAOSTAT. Statistic Division. Disponível em: <http://faostat3.fao.org/ compare/E>. Acesso em: 09 abr. 2016.

FUNDAÇÃO DE ECONOMIA E ESTATÍSTICA (FEE). FEE Dados. Disponível em: <http:// feedados.fee.tche.br/feedados/>. Acesso em: 18 jan. 2016.

GIACOMIN, George Scarpat; OHNUMA JR., Alfredo Akira. Análise de resultados de pegada hídrica por países e produtos específicos. Rev. Elet. em Gestão, Educação e Tecnologia Ambiental, v. 8, n. 8, p. 1562-1572, 2012.

HENDY, C. R. C.; KLEIH, U.; CRAWSHAW, R.; PHILLIPS, M.. Livestock and the environment finding a balance: Interactions between livestock production systems and the environment, Impact Domain: concentrate feed demand, Food and Agriculture Organization, Rome, Italy, 1995 . Disponível em: <www.fao.org/wairdocs/ lead/x6123e/x6123e00.htm\#Contents $>$. Acesso em: 01 set. 2016.

HOEKSTRA, A. Y. Human appropriation of natural capital: A comparison of ecological footprint and water footprint analysis. Ecological Economics, n. 68, p. 1963-1974, 2009.

HOEKSTRA, A. Y.; CHAPAGAINS, A. K.; ALDAYA, M. M.; MEKONNEN, M. M. Manual de avaliação da pegada hídrica: estabelecendo o padrão global. São Paulo, 2011. 
HOTT, M. C.; CARVALHO, G. R.; OLIVEIRA, A. F. de. Uso de Sistemas de Informações Geográficas na Análise de Concentração da Produção Láctea no Brasil. Campinas: Embrapa, 2007.

INSTITUTO BRASILEIRO DE GEOGRAFIA E ESTATÍSTICA - IBGE. Pesquisa Pecuária Municipal, 2014. Disponível em: <http://www. sidra.ibge.gov.br/bda/pesquisas/ppm/default. asp?o=28\&i=P>. Acesso em: 09 abr. 2016. Acesso em: 18 jan. 2016.

MEKONNEN, M. M.; HOEKSTRA, A. Y. The green, blue and grey water footprint of farm animals and animal products. Value of Water Research Series, n. 48, UNESCO-IHE, Delft, the Netherlands, 2010.

OKANO, M. T.; VENDRAMETTO, O.; SANTOS, O. S.. Construção de indicadores e métodos para a classificação de produtores de leite para a melhoria de desempenho dos sistemas de produção. GEPROS - Gestão da Produção, Operações e Sistemas, Bauru, v. 8, n. 4, p. 4559, 2013.

SCHMACHER, Gabriela; MARION FILHO, Pascoal José. A expansão da Pecuária no Rio Grande do Sul e o transbordamento na produção de Leite (2000 a 2010). Gestão \& Regionalidade, São Caetano do Sul, v. 29, n. 87, p. 32-46, 2013.

SERÉ, C.; STEINFELD, H. World livestock production systems: current status, issues and trends, Animal Production and Health Paper 127, Food and Agriculture Organization, Rome, Italy, 1996. Disponível em: <http://www.fao. org/3/a-w0027e.pdf>. Acesso em: 01 set. 2016. 


\section{APENNDICE - TABELAS COM INFORMAÇÕES POR COREDE}

Tabela 1 - Cabeças, produção, produtividade, média de conversão de alimento e pegada hídrica dos municípios do Corede Fronteira Noroeste em 2014

\begin{tabular}{cccccc}
\hline Municípios & Cabeças & $\begin{array}{c}\text { Produção } \\
\text { (mil litros) }\end{array}$ & Produtividade & $\begin{array}{c}\text { Média conversão } \\
\text { alimentação }(\mathrm{kg} \\
\text { alimento/kg prod.) }\end{array}$ & $\begin{array}{c}\text { Pegada hídrica } \\
\left(\mathrm{I}_{\mathrm{a}} / \mathrm{I}_{\mathrm{l}}\right)\end{array}$ \\
\hline Alecrim & 3.212 & 13.350 & $4.156,29$ & 0,88 & 364,437 \\
Alegria & 3.425 & 12.954 & $3.782,19$ & 0,96 & 400,484 \\
Boa Vista do Buricá & 5.567 & 25.456 & $4.572,66$ & 0,80 & 331,253 \\
Campina das Missões & 9.450 & 26.051 & $2.756,72$ & 1,32 & 549,460 \\
Cândido Godói & 9.450 & 27.783 & $2.940,00$ & 1,24 & 515,206 \\
Doutor Maurício Car- & 3.468 & 14.147 & $4.079,30$ & 0,89 & 371,316 \\
doso & 5.084 & 20.691 & $4.069,83$ & 0,89 & 372,180 \\
Horizontina & 4.802 & 16.425 & $3.420,45$ & 1,06 & 442,838 \\
Independência & 5.696 & 22.870 & $4.015,10$ & 0,91 & 377,253 \\
Nova Candelária & 2.276 & 7.037 & $3.091,83$ & 1,18 & 489,906 \\
Novo Machado & 5.750 & 11.730 & $2.040,00$ & 1,78 & 742,503 \\
Porto Lucena & 2.350 & 8.961 & $3.813,19$ & 0,95 & 397,228 \\
Porto Mauá & 1.450 & 3.824 & $2.637,24$ & 1,38 & 574,353 \\
Porto Vera Cruz & 8.170 & 32.806 & $4.015,42$ & 0,91 & 377,222 \\
Santa Rosa & 15.601 & 62.640 & $4.015,13$ & 0,91 & 377,250 \\
Santo Cristo & 3.772 & 13.414 & $3.556,20$ & 1,02 & 425,933 \\
São José do Inhacorá & 4.114 & 14.400 & $3.500,24$ & 1,04 & 432,743 \\
Senador Salgado Filho & 10.995 & 44.146 & $4.015,10$ & 0,91 & 377,253 \\
Três de Maio & 3.727 & 13.606 & $3.650,66$ & 1,00 & 414,913 \\
Tucunduva & 2.598 & 6.235 & $2.399,92$ & 1,52 & 631,148 \\
Tupandi & & & &
\end{tabular}

Fonte: elaborada pelos autores.

Tabela 2 - Cabeças, produção, produtividade, média de conversão de alimento e pegada hídrica dos municípios do Corede Produção em 2014

\begin{tabular}{cccccc}
\hline Municípios & Cabeças & $\begin{array}{c}\text { Produção } \\
\text { (mil litros) }\end{array}$ & Produtividade & $\begin{array}{c}\text { Média conversão } \\
\text { alimentação (kg ali- } \\
\text { mento/kg prod.) }\end{array}$ & $\begin{array}{c}\text { Pegada hídri- } \\
\text { ca }\left(I_{\mathrm{a}} / \mathrm{I}_{\mathrm{l}}\right)\end{array}$ \\
\hline Almirante Tamandaré do Sul & 3.000 & 12.000 & $4.000,00$ & 0,91 & 378,677 \\
Camargo & 4.074 & 19.555 & $4.799,95$ & 0,76 & 315,567 \\
Carazinho & 1.603 & 5.049 & $3.149,72$ & 1,16 & 480,902 \\
Casca & 10.216 & 55.166 & $5.399,96$ & 0,67 & 280,503 \\
Ciríaco & 4.727 & 20.326 & $4.299,98$ & 0,85 & 352,259 \\
Coqueiros do Sul & 4.525 & 17.648 & $3.900,11$ & 0,93 & 388,375 \\
Coxilha & 3.573 & 17.508 & $4.900,08$ & 0,74 & 309,118 \\
David Canabarro & 5.351 & 25.952 & $4.849,93$ & 0,75 & 312,315 \\
Ernestina & 2.987 & 11.649 & $3.899,90$ & 0,93 & 388,396 \\
Gentil & 2.987 & 11.649 & $3.899,90$ & 0,93 & 388,396 \\
Marau & 9.414 & 45.187 & $4.799,98$ & 0,76 & 315,565 \\
Mato Castelhano & 2.206 & 9.927 & $4.500,00$ & 0,81 & 336,601 \\
Muliterno & 2.340 & 9.828 & $4.200,00$ & 0,87 & 360,644 \\
Nova Alvorada & 2.850 & 13.125 & $4.605,26$ & 0,79 & 328,908 \\
Passo Fundo & 6.749 & 32.395 & $4.799,97$ & 0,76 & 315,566 \\
Pontão & 5.719 & 29.167 & $5.100,02$ & 0,71 & 297,000
\end{tabular}




\begin{tabular}{cccccc} 
Santo Antônio do Palma & 2.377 & 11.766 & $4.949,94$ & 0,74 & 306,005 \\
Santo Antônio do Planalto & 1.630 & 5.163 & $3.167,48$ & 1,15 & 478,205 \\
São Domingos do Sul & 2.452 & 12.137 & $4.949,84$ & 0,74 & 306,011 \\
Vanini & 1.712 & 8.492 & $4.960,28$ & 0,73 & 305,367 \\
Vila Maria & 8.479 & 40.699 & $4.799,98$ & 0,76 & 315,565 \\
\hline Fonte:
\end{tabular}

Tabela 3 - Cabeças, produção, produtividade, média de conversão de alimento e pegada hídrica dos municípios do Corede Vale do Taquari em 2014

\begin{tabular}{|c|c|c|c|c|c|}
\hline Municípios & Cabeças & $\begin{array}{l}\text { Produção } \\
\text { (mil litros) }\end{array}$ & Produtividade & $\begin{array}{l}\text { Média conversão } \\
\text { alimentação (kg ali- } \\
\text { mento/kg prod.) }\end{array}$ & $\begin{array}{l}\text { Pegada hídrica } \\
\left(I_{a} / l_{1}\right)\end{array}$ \\
\hline Anta Gorda & 6.750 & 20.230 & $2.997,04$ & 1,21 & 505,401 \\
\hline Arroio do Meio & 8.000 & 26.300 & $3.287,50$ & 1,11 & 460,747 \\
\hline Arvorezinha & 2.875 & 6.980 & $2.427,83$ & 1,50 & 623,894 \\
\hline Bom Retiro do Sul & 4.040 & 9.090 & $2.250,00$ & 1,62 & 673,203 \\
\hline Canudos do Vale & 2.495 & 6.000 & $2.404,81$ & 1,51 & 629,865 \\
\hline Capitão & 1.800 & 7.000 & $3.888,89$ & 0,94 & 389,496 \\
\hline Colinas & 2.150 & 8.250 & $3.837,21$ & 0,95 & 394,742 \\
\hline Coqueiro Baixo & 2.100 & 6.940 & $3.304,76$ & 1,10 & 458,341 \\
\hline Cruzeiro do Sul & 4.500 & 13.700 & $3.044,44$ & 1,20 & 497,531 \\
\hline Dois Lajeados & 3.110 & 9.221 & $2.964,95$ & 1,23 & 510,870 \\
\hline Doutor Ricardo & 1.300 & 3.600 & $2.769,23$ & 1,31 & 546,977 \\
\hline Encantado & 1.650 & 5.440 & $3.296,97$ & 1,10 & 459,424 \\
\hline Estrela & 8.250 & 40.990 & $4.968,48$ & 0,73 & 304,863 \\
\hline Fazenda Vilanova & 1.930 & 7.719 & $3.999,48$ & 0,91 & 378,726 \\
\hline Forquetinha & 2.330 & 8.390 & $3.600,86$ & 1,01 & 420,651 \\
\hline Ilópolis & 1.135 & 4.125 & $3.634,36$ & 1,00 & 416,774 \\
\hline Imigrante & 2.400 & 7.700 & $3.208,33$ & 1,13 & 472,116 \\
\hline Lajeado & 1.000 & 2.250 & $2.250,00$ & 1,62 & 673,203 \\
\hline Marques de Souza & 3.600 & 11.500 & $3.194,44$ & 1,14 & 474,169 \\
\hline Muçum & 860 & 2.470 & $2.872,09$ & 1,27 & 527,388 \\
\hline Nova Bréscia & 1.950 & 7.130 & $3.656,41$ & 1,00 & 414,260 \\
\hline Paverama & 2.300 & 6.900 & $3.000,00$ & 1,21 & 504,902 \\
\hline Poço das Antas & 600 & 1.365 & $2.275,00$ & 1,60 & 665,805 \\
\hline Pouso Novo & 2.135 & 8.970 & $4.201,41$ & 0,87 & 360,524 \\
\hline Progresso & 3.160 & 11.300 & $3.575,95$ & 1,02 & 423,582 \\
\hline Putinga & 4.700 & 14.445 & $3.073,40$ & 1,18 & 492,843 \\
\hline Relvado & 2.790 & 6.950 & $2.491,04$ & 1,46 & 608,062 \\
\hline Roca Sales & 3.300 & 8.000 & $2.424,24$ & 1,50 & 624,816 \\
\hline Santa Clara do Sul & 2.800 & 7.920 & $2.828,57$ & 1,29 & 535,502 \\
\hline Sério & 1.900 & 4.350 & $2.289,47$ & 1,59 & 661,596 \\
\hline Tabaí & 320 & 832 & $2.600,00$ & 1,40 & 582,579 \\
\hline Taquari & 480 & 1.500 & $3.125,00$ & 1,17 & 484,706 \\
\hline Teutônia & 8.100 & 36.292 & $4.480,49$ & 0,81 & 338,067 \\
\hline Travesseiro & 2.700 & 10.360 & $3.837,04$ & 0,95 & 394,759 \\
\hline Vespasiano Correa & 4.500 & 21.000 & $4.666,67$ & 0,78 & 324,580 \\
\hline Westfália & 3.425 & 15.800 & $4.613,14$ & 0,79 & 328,346 \\
\hline
\end{tabular}

Fonte: elaborada pelos autores. 